\title{
Endoscopic Ultrasound-Guided Angiotherapy for Gastric Varices-A Small Retrospective Study
}

\author{
Kapil Sharma ${ }^{1}$ Mamta Sharma ${ }^{2}$ Sanchit Singh ${ }^{1}$

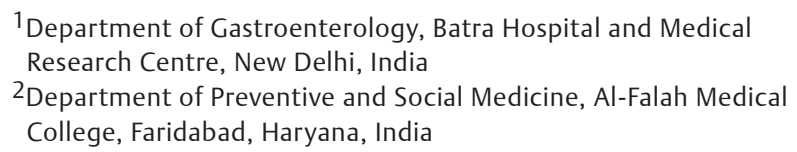

Address for correspondence Kapil Sharma, MD, DM, Department of Gastroenterology, Batra Hospital and Medical Research Centre, New Delhi 110062, India (e-mail: drkapilsharma83@gmail.com).

J Digest Endosc:2020;11:201-204

\begin{abstract}
Introduction Conventional $n$-butyl-cyanoacrylate (CYA) recommended for secondary prophylaxis of gastric varices (GV) is associated with significant rebleeding and glue embolism. Limited data are available on more successful and less risky endoscopic ultrasound-guided coils and CYA (EUS-Coils-CYA) injection in GV.

Methods We present a retrospective case series of 12 patients with GV bleeding managed successfully with EUS-Coils-CYA injection leading to variceal eradication in 11 patients.

Results From January 2018 to June 2019, 12 cases of GV, which were either bleed-

Keywords

- gastric varices

- coil

- cyanoacrylate glue and EUS ing or bled recently, were included. Complete obliteration was achieved in $91.6 \%$ of patients with $100 \%$ technical success. Mean number of deployed coils and volume of injected CYA glue were 1.16 and $1.58 \mathrm{~mL}$, respectively.

Conclusions EUS-guided angiotherapy is an effective and safe intervention for managing GV bleeding with high technical success rate.
\end{abstract}

\section{Introduction}

Gastric variceal (GV) bleeding contributes 10 to $30 \%$ to all variceal hemorrhages. ${ }^{1}$ Cyanoacrylate (CYA) glue injection in GV was first described by Soehendra et al. ${ }^{2}$ It has higher hemostasis and lower rebleeding rates compared with band ligation or sclerotherapy. ${ }^{3-5}$ Risk of embolization always remains high in free-hand CYA injection despite being effective that has led to the development of alternative treatment modalities, including balloon-occluded retrograde transvenous obliteration (BRTO) and endoscopic ultrasound (EUS)-guided injection of coils, CYA glue, or both. ${ }^{6}$ These coils obliterate GV by causing variceal thrombosis, 7,8 and when used in combination with CYA glue injection, these coils reduce the risk of glue embolization. Synthetic fibers ("wool coils") covering the coils function as scaffolds to retain CYA glue intravariceally and decrease the amount of glue injection needed to achieve obliteration.

\section{Methods}

\section{Patients}

A retrospective review of patients, who were treated with EUS-Coils-CYA glue injection for GV from January 2018 to June 2019, was done.

Patients who had gastroesophageal varices type 2 (GOV2) or isolated GV type 1 (IGV1) according to Sarin classification ${ }^{9}$ with active or recent upper GI bleeding attributed to GV were enrolled. Prior to endoscopy, all patients received injection ceftriaxone, injection terlipressin, fluids, blood, and blood products as required.

Patients who had prior endotherapy, BRTO, or transjugular intrahepatic portosystemic shunt for variceal bleed, hepatic encephalopathy grade III/IV, cardiorespiratory failure, and pregnancy were excluded

Standard diagnostic upper endoscopy was performed before procedure. Endoscopic stigmata of bleeding were recorded. 


\section{Procedure}

Procedure was performed in a single center in endoscopy suite by a single endoscopist. Procedure was performed under sedation in all patients.

EUS was performed using a Pentax EG 3870 UTK linear echoendoscope. Transesophageal-transcrural approach was preferred in case of IGV1 and transgastric approach for GOV2. Intragastric water instillation, tissue harmonics, and zoom were used for better imaging of GV. Color Doppler was used to detect the active flow and pulse Doppler was used to identify afferent and efferent channels of GV. GV within the wall of stomach were labeled as intramural varices and outside the wall were labeled as para-GV. Echo Tip Ultra ultrasound (Cook Medical Bloomington, IN, United Statesl) needle, 0.035-inch Nester embolization coil, MReye coil from cook medical, and $n$-butyl CYA glue (Endocryl, Samarth Life Sciences, Mumbai, Maharashtra, India) were used. HF 49 Plus (3.5 KW) C arm machine with image intensifier (Allengers Medical Ltd. Chandigarh, India) was used for fluoroscopy during EUS-guided coiling.

\section{Procedure Steps}

Procedure steps were same as described for EUS-CoilsCYA injection. ${ }^{10}$ Relook endoscopy was done immediately postprocedure to see for any bleeding at injection site. All patients were admitted and monitored for any adverse event for 48 hours, especially for rebleeding.

Repeat upper endoscopy and EUS were scheduled at 1 and 3 months, followed by 6-month surveillance examinations. Any clinical suspicion of recurrent gastrointestinal bleeding was immediately investigated. Each bleeding episode was recorded as a separate event to allow assessment of hemostasis, adverse events, and calculation of posttreatment bleeding rates.

\section{Results}

All patients had liver cirrhosis. One patient had Child $A$, nine patients had Child $B$, and two patients had Child $C$ cirrhosis. Ethanol as etiology in 7 and a Child-Turcotte-Pugh score of 7 and 9 were most commonly noted in the study (-Table $\mathbf{1}$ ). At the time of EUS-Coils-CYA injection, seven patients had GOV2 and five patients had IGV1 on endoscopy (-Fig. 1A). Seven patients had last variceal bleeding more than 1 week before the procedure and five patients had last variceal bleeding within a week. One of these five patients had active bleeding at the time of procedure (-Fig. 1B). Variceal obliteration was confirmed endoscopically by obliterated variceal conglomerate with earth crack appearance (-Fig. 1C) in all patients. Extrusion of coil from obliterated GV was noticed in one patient during follow-up endoscopy ( - Fig. 1D). Coils were successfully placed in all patients (-Fig. 2B). A single coil was placed in 10 patients and two coils in 2 patients. Nester embolization coil diameter of 12 to $16 \mathrm{~mm}$ and MReye coil of 5 to $10 \mathrm{~mm}$ diameter were selected according to short-axis diameter of GV and $20 \%$ excess was calculated over varix diameter. Mean number of deployed coils was 1.16. In addition, 1 to $3 \mathrm{~mL}$ of CYA glue was injected in all the patients for complete obliteration of GV and mean volume of CYA injection was $1.58 \mathrm{~mL}$. Variceal obliteration was confirmed endosonographically ( $\mathbf{- F i g . ~ 2 C )}$ by lack of color Doppler signal and appearance of echogenicity within intramural varices immediately after endotherapy. Fluoroscopy was also used in this study to visualize coil migration if any during procedure and follow-up. Conglomerated coils were well localized in fluoroscopy during procedure (-Fig. 3). Puncture site minor bleeding was noted in three patients, which settled down without any intervention. During 18

Table 1 Baseline characteristics of enrolled patients and specifications of coils (first, middle, and last two digits indicate size of recommended end hole diameter of EUS FNA needle in inch, extended coil embolus length, and coiled embolus diameter, respectively)

\begin{tabular}{|l|l|l|l|l|l|l|}
\hline SN & Age/sex & Etiology/CTP score & $\begin{array}{l}\text { Classification and grading } \\
\text { of gastric varices }{ }^{2}\end{array}$ & $\begin{array}{l}\text { No of } \\
\text { coils }\end{array}$ & $\begin{array}{l}\text { Specifications of } \\
\text { coils }\end{array}$ & $\begin{array}{l}\text { Amount of CYA } \\
\text { glue (mL) }\end{array}$ \\
\hline 1 & $43 / \mathrm{M}$ & Ethanol/6 & GOV2/F2 & 1 & $35-14-12$ & 2 \\
\hline 2 & $54 / \mathrm{F}$ & HBV/9 & IGV1/F3 & 2 & $\begin{array}{l}35-14-10, \\
35-8-8\end{array}$ & 1 \\
\hline 3 & $42 / \mathrm{M}$ & Ethanol/7 & GOV2/F2 & 1 & $35-14-8$ & 2 \\
\hline 4 & $48 / \mathrm{M}$ & HBV/8 & GOV2/F2 & 1 & $35-14-12$ & 1 \\
\hline 5 & $58 / \mathrm{M}$ & Ethanol/9 & GOV2/F2 & 1 & $35-14-12$ & 1 \\
\hline 6 & $49 / \mathrm{M}$ & Ethanol/7 & IGV1/F2 & 1 & $35-10-10$ & 2 \\
\hline 7 & $61 / \mathrm{F}$ & NASH/8 & GOV2/F3 & $35-14-12$, & 1 \\
\hline 8 & $39 / \mathrm{F}$ & HCV/9 & IGV1/F3 & 1 & $35-10-10$ & 3 \\
\hline 9 & $41 / \mathrm{M}$ & Ethanol/7 & IGV1/F2 & 1 & $35-14-20$ & 2 \\
\hline 10 & $53 / \mathrm{M}$ & Ethanol/8 & IGV1/F2 & 1 & $35-14-8$ & 1 \\
\hline 11 & $44 / \mathrm{M}$ & Ethanol/10 & GOV2/F2 & 1 & $35-14-12$ \\
\hline 12 & $56 / \mathrm{M}$ & NASH/11 & GOV2/F2 & $35-10-10$ & 1 \\
\hline
\end{tabular}

Abbreviation: CTP, Child-Turcotte-Pugh; CYA, cyanoacrylate; EUS, endoscopic ultrasound; FNA, fine-needle aspiration; GOV2, gastroesophageal varices type 2; HBV, hepatitis B virus; HCV, hepatitis C virus; IGV1, isolated GV type 1; NASH, nonalcoholic steatohepatitis. 

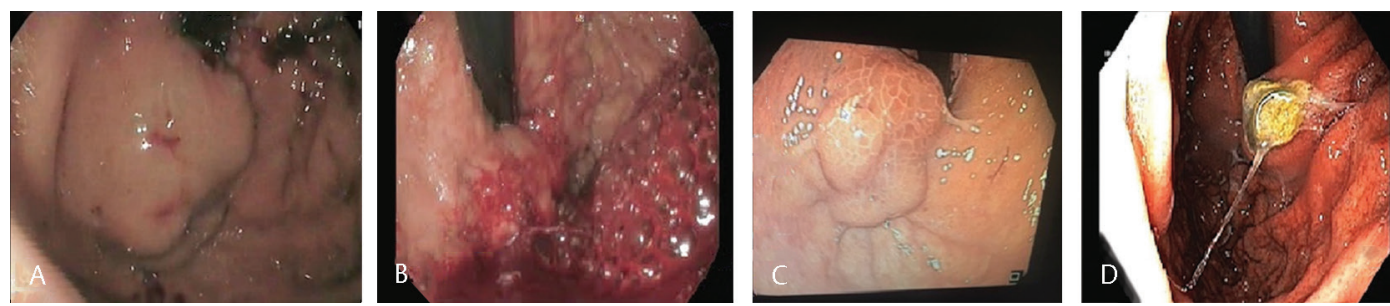

Fig. 1 Endoscopic imaging of gastric varices. (A) Gastric varices (IGV1/F2), (B) actively bleeding gastric varices, (C) crack on earth appearance of obliterated gastric varices, and (D) extrusion of coil from obliterated gastric varices.
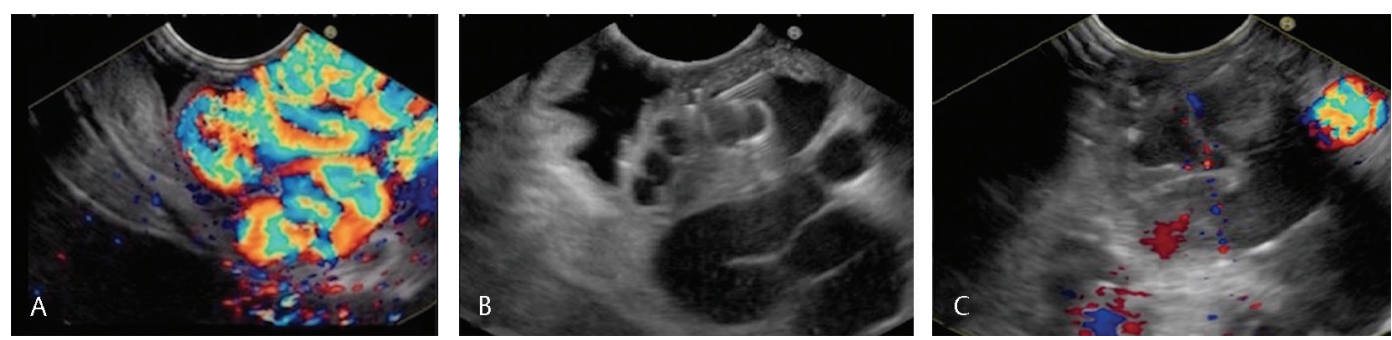

Fig. 2 Endoscopic ultrasound (EUS) imaging of gastric varices. (A) Color Doppler showing active flow in gastric varices and (B) coil deployment in gastric varices endosonographically; (C) lack of color Doppler signal on EUS suggests obliterated gastric varices.

months follow-up, only one patient rebled that was controlled by conventional CYA glue alone.

\section{Discussion}

Bleeding from GV is associated with high risk of mortality and can be tackled with EUS-Coils-CYA injection with less risk of embolism. The limitation of visualization in setting of active bleeding from GV can be overcome by implementation of EUS and Doppler effect. ${ }^{11}$

Romero-Castro et $\mathrm{al}^{12}$ demonstrated GV eradication rate of $75 \%$ when used as a monotherapy without any migration or complication using MReye coils into the perforating feeding vein. Fujii-Lau et $\mathrm{al}^{8}$ demonstrated complete obliteration of GV in $93 \%$ patients by EUS-Coils-CYA injection with an average of 1.4 coils and $2 \mathrm{~mL}$ of CYA glue per patient. Combination of coils and CYA glue in the afferent portion of the perforator has reported complete variceal obliteration in $96.6 \%$ of cases with $100 \%$ technical success rate and immediate disappearance of GV in $80 \%$ of patients in a recent study. ${ }^{13} \mathrm{~A}$ recent systemic review and meta-analysis ${ }^{14}$ showed that EUS-guided angiotherapy is safe and effective procedure with high technical success rate.

In large GV, multiple coils can be used in a single session. Diameter of the first coil should be greater than diameter of targeted intramural GV in short axis and diameter of subsequent coils should be smaller than the previously injected coil. Large diameter coils negate the risk of embolism and smaller coils produce larger surface area, which is more favorable for the adsorption of CYA to block the blood flow. Nester and MReye embolization coils are currently being used for EUS guided angiotherapy ( - Table 2 ). Recanalization of obliterated intramural GV was not seen despite patent perforator and para-GV in our study that needs to be confirmed further.

Retrospective case series, short follow-up, single-center experience, and small sample size were the major limitations of our study.

In conclusion, our retrospective case series showed that EUS-Coils-CYA injection is an effective and safe endoscopic technique with high technical success rate for the management of GV bleeding. 


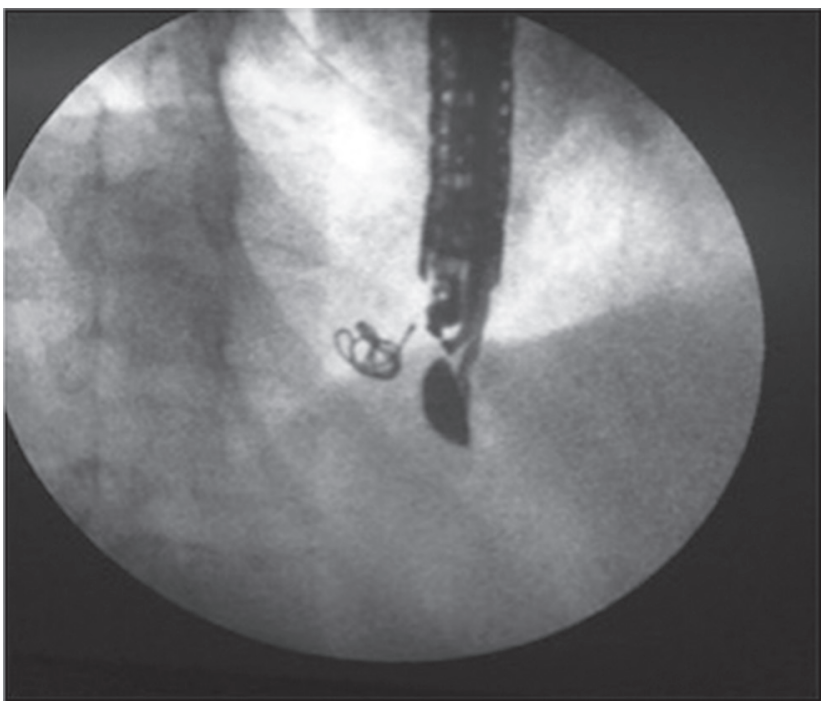

Fig. 3 Fluoroscopy showing conglomerate of deployed coils.

Table 2 Comparison between Nester and MReye embolization coils

\begin{tabular}{|l|l|l|}
\hline & $\begin{array}{l}\text { Nester } \\
\text { embolization coil }\end{array}$ & $\begin{array}{l}\text { MReye } \\
\text { embolization coil }\end{array}$ \\
\hline Material & Soft platinum & Stainless steel \\
\hline Configuration & $\begin{array}{l}\text { Designed for 0.018- } \\
\text { and 0.035-inch } \\
\text { diameter systems }\end{array}$ & $\begin{array}{l}\text { Designed for 0.035- } \\
\text { and 0.038-inch } \\
\text { diameter systems }\end{array}$ \\
\hline Radial force & Low & High \\
\hline Thrombogenicity & High & Very high \\
\hline Attached fibers & Long & Extra long \\
\hline $\begin{array}{l}\text { Preferable injection } \\
\text { site of gastric } \\
\text { varices }\end{array}$ & $\begin{array}{l}\text { Low flow system } \\
\text { like intramural } \\
\text { varices }\end{array}$ & $\begin{array}{l}\text { High-flow system } \\
\text { like perforators }\end{array}$ \\
\hline
\end{tabular}

\section{Funding}

None.

\section{Conflict of Interest}

None declared.

\section{References}

1 Sarin SK, Lahoti D, Saxena SP, Murthy NS, Makwana UK. Prevalence, classification and natural history of gastric varices: a long-term follow-up study in 568 portal hypertension patients. Hepatology 1992;16(6):1343-1349

2 Soehendra N, Nam VC, Grimm H, Kempeneers I. Endoscopic obliteration of large esophagogastric varices with bucrylate. Endoscopy 1986;18(1):25-26
3 Garcia-Tsao G, Sanyal AJ, Grace ND, Carey W; Practice Guidelines Committee of the American Association for the Study of Liver Diseases. Practice Parameters Committee of the American College of Gastroenterology. Prevention and management of gastroesophageal varices and variceal hemorrhage in cirrhosis. Hepatology 2007;46(3):922-938

4 de Franchis R, Baveno VI; Baveno VI Faculty. Expanding consensus in portal hypertension: report of the Baveno VI Consensus Workshop: stratifying risk and individualizing care for portal hypertension. J Hepatol 2015;63(3):743-752

5 Sarin SK. Long-term follow-up of gastric variceal sclerotherapy: an eleven-year experience. Gastrointest Endosc 1997;46(1):8-14

6 Irani S, Kowdley K, Kozarek R. Gastric varices: an updated review of management. J Clin Gastroenterol 2011;45(2):133-148

7 Bhat YM, Weilert F, Fredrick RT, et al. EUS-guided treatment of gastric fundal varices with combined injection of coils and cyanoacrylate glue: a large U.S. experience over 6 years (with video) Gastrointest Endosc 2016;83(6):1164-1172

8 Fujii-Lau LL, Law R, Wong Kee Song LM, Gostout CJ, Kamath PS, Levy MJ. Endoscopic ultrasound (EUS)-guided coil injection therapy of esophagogastric and ectopic varices. Surg Endosc 2016;30(4):1396-1404

9 Sarin SK, Kumar A. Gastric varices: profile, classification, and management. Am J Gastroenterol 1989;84(10):1244-1249

10 Mukkada RJ, Antony R, Chooracken MJ, et al. Endoscopic ultrasound-guided coil or glue injection in post-cyanoacrylate gastric variceal re-bleed. Indian J Gastroenterol 2018;37(2): 153-159

11 Bhatia V. Endoscopic ultrasound (EUS) for esophageal and gastric varices: how can it improve the outcomes and reduce complications of glue injection. J Clin Exp Hepatol 2012;2(1):70-74

12 Romero-Castro R, Pellicer-Bautista F, Giovannini M, et al. Endoscopic ultrasound (EUS)-guided coil embolization therapy in gastric varices. Endoscopy 2010;42(Suppl 2) :E35-E36

13 Robles-Medranda C, Valero M, Nebel JA, et al. Endoscopic-ultrasound-guided coil and cyanoacrylate embolization for gastric varices and the roles of endoscopic Doppler and endosonographic varicealography in vascular targeting. Dig Endosc 2019;31(3):283-290

14 McCarty TR, Bazarbashi AN, Hathorn KE, Thompson CC, Ryou M. Combination therapy versus monotherapy for EUS-guided management of gastric varices: a systematic review and meta-analysis. Endosc Ultrasound 2020;9(1):6-15 